\section{Beliefs and trends of aesthetic surgery in South Korean young adults}

\author{
Rachel H. Park', Paige L. Myers ${ }^{2}$, Howard N. Langstein ${ }^{2}$ \\ ${ }^{1}$ University of Rochester School of Medicine and Dentistry, Rochester, NY; ${ }^{2}$ Division \\ of Plastic and Reconstructive Surgery, University of Rochester Medical Center, \\ Rochester, NY, USA
}

Correspondence: Rachel H. Park

University of Rochester School of Medicine and Dentistry, Box 287, 601 Elmwood Ave, Rochester, NY 14642, USA

Tel: +1-571-428-7278, Fax: +1-585-276-1985,E-mail: rachel_park@urmc.rochester.edu

This study was generously supported by University of Rochester School of Medicine and Dentistry Office of Medical Education Summer Research Funding.

This article was presented at the Northeastern Society of Plastic Surgeons (NESPS) on October 26, 2018, in Boston, MA, USA.

Received: August 18, 2018 • Revised: March 19, 2019 • Accepted: March 26, 2019 pISSN: 2234-6163・elSSN: 2234-6171

https://doi.org/10.5999/aps.2018.01172 • Arch Plast Surg 2019;46:612-616

Copyright (C) 2019 The Korean Society of Plastic and Reconstructive Surgeons

This is an Open Access article distributed under the terms of the Creative Commons Attribution

Non-Commercial License (http://creativecommons.org/licenses/by-nc/4.0/) which permits

unrestricted non-commercial use, distribution, and reproduction in any medium, provided the original work is properly cited.

\section{Lookism and aesthetic plastic surgery in South Korea}

Introduction

In 2003, the word “외모지상주의 (oe-mo-ji-sang-ju-ui)" first made an appearance in the neologism dictionary of the National Institute of Korean Language. The closest English translation to this word is "lookism," which was first used in 1978 in the Washington Post magazine [1]. The term is defined as "prejudice or discrimination based on physical appearance" that falls short of the societal notions of beauty [2]. With the rise of "lookism" in South Korea, plastic surgery has grown from a subculture into a mainstream culture that penetrated deeply into the society. External appearance is now considered a pivotal factor that contributes to professional achievements and interpersonal relationships [3]. Correlation between attractiveness and success is not a new concept nor is it limited to South Korea [4]; however, over recent decades this phenomenon of "lookism" has led many individuals to pursue cosmetic surgery as a means for reaching social and professional success.

Through electronic surveys and personal interviews, the attitudes and beliefs surrounding aesthetic surgery of young adults in South Korea are explored. More specifically, Korean young adults' viewpoints and motivations to undergo plastic surgery are addressed, including concerns regarding potential employment. Finally, differences between male and female participants are investigated to assess if there are any gender-specific opinions toward aesthetic surgery procedures.
Methods

After obtaining University of Rochester Research Subjects Review Board approval (RSRB 00057399), volunteers in South Korea were recruited through online advertisements posted on the three major job-searching Internet forums on "naver.com," the largest search engine in South Korea. The posting included the study information, as well as the link to the survey. The survey was open for 6 weeks and advertisements were posted three times throughout the open enrollment period. Currently unemployed South Korean men and women between the ages of 18 and 29 with college or higher degree who were seeking future employment were included in the study. Current college students were also included in the study. Incomplete surveys or individuals with current part-time or full-time jobs were excluded from the study.

The online survey was generated by REDcap (Nashville, TN, USA). This is a secure, web-based application for building and managing an online survey database. Individuals who were interested in the personal interviews were instructed to contact the principal investigator via email. All interviews were recorded on the investigator's password-secured iPhone. The data was collected and processed by the REDcap application and all statistical analysis performed using Microsoft Excel (Redmond, Washington, USA) and R (R Studio Inc., Boston, MA, USA). All subjects who participated in the survey were entered into a raffle to win a gift card $(100,000 \mathrm{KRW}$, equivalent to $\$ 89.7$ USD as of June 15,2015 ) [5]. All subjects who participated in personal interviews were paid an amount equal to $15,000 \mathrm{KRW}$ (equivalent to $\$ 13.5$ USD as of June 15,2015 ) at the conclusion of the interview.

\section{Results}

A total of 103 South Korean individuals (76 females, 27 males) completed the online survey. Nineteen participants volunteered for personal interviews (11 females, 8 males) (Table 1). Among the volunteers, 21 individuals indicated that they had aesthetic procedures done in the past. Females had a higher rate of past plastic surgery experience $(22.4 \%)$ compared to males (14.8\%). More males (39.1\%) compared to females (28.8\%) without any previous history of plastic surgery expressed interest in doing so in the future (Table 2).

Most of the survey participants indicated that undergoing plastic surgery would have a "very positive" or "positive" effect in the hiring process with an average score of 1.95 out of 5 , where 1 corresponds to "very positive effect" and 5 to "very negative effect" (Table 3). No significant differences were observed between genders or between the groups with and without plastic surgery experience (Table 3 ).

The most common reason (60\%) for pursuing plastic surgery was personal dissatisfaction with external appearance. Parental influence was the second most popular reason overall (20\%); however, greater for women than men ( $21 \%$ and $15 \%$, respectively). Employment was a motivating factor for men (6\%) though none of the female survey participants indicated employment as the primary reason (Table 4). During the personal interviews, however, all the participants indicat- 


\section{Table 1. Participant characteristics}

\begin{tabular}{|lccc|}
\hline & Male & Female & Total \\
\hline Online survey & 27 & 76 & 103 \\
Personal interview & 8 & 11 & 19 \\
Field of study & $\begin{array}{l}\text { Accounting, IT media, urban engineering, chemical } \\
\text { engineering, computer engineering, mechanical } \\
\text { engineering, medical treatment engineering, economics, } \\
\text { psychology, biomechanics, social welfare, business } \\
\text { management, geography, public administration, } \\
\text { mathematics, applied mathematics, media, English, Korean, } \\
\text { Japanese, Chinese, history, pharmacology, international } \\
\text { relations, life science, nursing, medicine, pedology, fine } \\
\text { arts, law, design, chemistry }\end{array}$ \\
\hline
\end{tabular}

Table 2. Past and future plastic surgery experience

\begin{tabular}{|ccr|}
\hline & Past experience & Future plan \\
\hline Male & & \\
Yes & $4(15)$ & $9(39)$ \\
No & $23(85)$ & $14(61)$ \\
Female & & \\
Yes & $17(22)$ & $17(29)$ \\
No & $59(78)$ & $42(71)$ \\
Total & & \\
Yes & $21(20)$ & $26(32)$ \\
No & $82(80)$ & $56(68)$ \\
\hline
\end{tabular}

Values are represented as number (\%).

ed that attractiveness is an important factor when seeking employment such that plastic surgery would be beneficial. Interestingly, participants indicated this is more helpful for potential females job applicants than males. Many interviewees associated positive personal traits with external attractiveness and negative personal traits with unattractiveness (Table 5), theoretically correlating to a higher likelihood of gaining employment.

\section{Importance of one's attractiveness-perspectives of young Korean adults}

Aesthetic surgery is prevalent in South Korea as external appearance is considered as an important factor for relationships and achievements, especially for women compared to men. An overwhelming majority (86\%) from the 2015 Gallup Korean consumer report indicated that one's looks are an "important" part of life with $25 \%$ choosing "very important" [6]. In our study, the most common motivation for aesthetic surgery for both men and women was personal dissatisfaction with external appearance as "lookism" is prevalent among South Korean young adults due to complicated cultural stereotypes. Many of the interviewees believed that physical attractiveness correlated directly to popularity in social settings. Attractiveness is associated with positive stereotypes while unattractiveness is linked to negative stereotypes, as illustrated during our personal interviews. For instance, some of the negative descriptors used by volunteers includ-
Table 3. Perceived effect of plastic surgery on finding an employment position

\begin{tabular}{|lccrl|}
\hline & $\begin{array}{c}\text { People with past } \\
\text { plastic surgery } \\
\text { experience }\end{array}$ & $\begin{array}{c}\text { People who are planning } \\
\text { on getting plastic surgery } \\
\text { in the future }\end{array}$ & $\begin{array}{c}\text { Total } \\
\text { value }\end{array}$ & P-value \\
\hline Male & $1.75(4)$ & $1.88(8)^{\text {a) }}$ & $1.84(12)$ & 0.82 \\
Female & $2.0(14)^{b)}$ & $2.0(15)^{\mathrm{c})}$ & $2.0(29)$ & 1 \\
Total & $1.94(18)$ & $1.96(23)$ & $1.95(41)$ & 0.93 \\
\hline
\end{tabular}

Values are presented as mean of the scores with the number of participants (n). Scale: 1 = very positive effect, 2 =positive effect, $3=$ neither positive nor negative, $4=$ negative effect, $5=$ very negative effect.

${ }^{a}$ One participant responded "I do not know." This response was excluded during calculation; "bThee participants responded "I do not know." Excluded as above; 'TTo participants responded "I do not know." Excluded as above.

Table 4. Primary reason for receiving or planning to receive aesthetic procedure

\begin{tabular}{|lllcc|}
\hline Reason & Male & Female & Total & P-value \\
\hline Dissatisfaction with my look & $6(46)$ & $22(65)$ & $28(60)$ & 0.41 \\
Parents' influence & $2(15)$ & $7(21)$ & $9(20)$ & 1 \\
Friends' influence & 0 & 0 & 0 & - \\
Significant other's influence & 0 & 0 & 0 & - \\
For a better personal relationship & $1(8)$ & 0 & $1(2)$ & 0.61 \\
For a better chance of employment & $3(23)$ & 0 & $3(6)$ & 0.03 \\
Peer pressure & 0 & $3(9)$ & $3(6)$ & 0.66 \\
Medical reasons & 0 & $1(3)$ & $1(2)$ & 1 \\
Scar removal & $1(8)$ & 0 & $1(2)$ & 0.61 \\
Others & 0 & $1(3)$ & $1(2)$ & 1 \\
Total & 13 & 34 & 47 & \\
\hline Values are represented as number (\%). & & & \\
\hline
\end{tabular}

ed "lazy," "anti-social," and "incompetent," certainly not desirable characteristics in a potential employee.

Interestingly, only three survey participants, all being male, indicated "employment" as the primary reason for receiving surgery. Despite the popular belief that attractiveness is an important factor in being selected for employment, it was not the most significant reason for surgery. However, most survey participants indicated that aesthetic surgery would have a positive effect in obtaining employment, with some reporting that it would have a very positive effect. This was observed in all study participants, regardless of gender or a history of cosmetic plastic surgery. These survey results correlated well with the personal interviewees' responses in that all individuals stated that the external appearance is important in finding a job and that an aesthetic procedure to improve appearance would have a positive impact. Our study indicated that personal dissatisfaction and peer/ familial pressure are the primary motivations, yet increasing chance of employment may be an additional reason in the decision to undergo aesthetic surgery. Since women have much lower threshold to undergo plastic surgical procedures for personal and aesthetic reasons, employment likely acts as a secondary motivation, or an added benefit, despite the greater pressure to look attractive in professional 
Table 5. Themes explored during the interviews

\begin{tabular}{|c|c|}
\hline Theme & Exemplar \\
\hline Perceived effect of plastic surgery in finding a job & $\begin{array}{l}\text { I believe that getting aesthetic surgical procedures would be very helpful during the interviewing processes } \\
\text { because applicants' looks do matter, as I heard from some employers. } \\
\text { I believe that many of the companies and employers consider one's looks during the hiring process, so I think } \\
\text { getting plastic surgery would be helpful. } \\
\text { I believe that you are much less likely to be considered for a position if you are obese or ugly, even if you are } \\
\text { competent. To a certain extent, you are forced to undergo aesthetic procedures in order to get hired. }\end{array}$ \\
\hline $\begin{array}{l}\text { Role of one's attractiveness in a professional and social } \\
\text { settings }\end{array}$ & $\begin{array}{l}\text { If you are pretty or handsome, you will naturally have many friends. } \\
\text { I have seen attractive people getting unfair advantages during my past work experiences. }\end{array}$ \\
\hline Role of one's attractiveness in different genders & $\begin{array}{l}\text { I believe that Korean society puts a significant pressure on women to look pretty. This really forces them to } \\
\text { spend excessive time and money on make-up, hair, clothing, and even plastic surgery. } \\
\text { Men can get away with being overweight or unattractive much more easily than women. If you are a woman } \\
\text { who is overweight or unattractive, people will judge you harshly. }\end{array}$ \\
\hline Positive stereotypes associated with external attractiveness & Diligent, hard-working, friendly, intelligent, competent \\
\hline $\begin{array}{l}\text { Negative stereotypes associated with external } \\
\text { unattractiveness }\end{array}$ & Lazy, gives up easily, anti-social, incompetent \\
\hline Current trend of plastic surgery in the Korean society & $\begin{array}{l}\text { Media seems to be the most significant factor that has been making plastic surgery so popular. Everyone } \\
\text { wants to look like movie stars that they see on the television, even if that means undergoing plastic surgical } \\
\text { procedures. } \\
\text { Men undergoing plastic surgery is not so frowned upon anymore. People are very understanding of the fact } \\
\text { that men can be interested in beauty and fashion just as much as women. }\end{array}$ \\
\hline
\end{tabular}

settings. Furthermore, all interviewees agreed that "good looking" people are favored during the employment process. Many spoke from their personal experience as well as their colleague's experiences, while some beliefs were based on social media. Such results indicate that South Korean young adults may view external attractiveness as a favorable factor in the hiring process, rendering aesthetic surgery an important strategy to gain advantage when seeking employment.

\section{Lookism and its differing influence on male and female}

Another noteworthy finding is the double standard between gender and the importance of attractiveness. All personal interviewees, both male and female, expressed that women are under greater pressure to look attractive to improve their chance of employment. The 2015 Gallup Korean consumer report [6] demonstrated that $41 \%$ of young women between ages of 19 and 29 indicated that external appearances are a "very important" factor in life, compared to $29 \%$ of males. This difference is widely acknowledged, likely stemming from the traditional gender inequality in traditional South Korean society and workplace [7]. Men may traditionally prefer more attractive female co-workers, therefore making it inevitable that a woman's attractiveness to become a significant part of the employment evaluation. Such bias is further manifested as men have dominated most highlevel positions in the Korean workforce. As of 2014, less than 5\% of government leadership positions were held by women in South Korea, compared to $10 \%-20 \%$ in the United States and Canada and even greater than $20 \%$ in some European counties such as Norway, Sweden, and United Kingdom [8]. Many interviewees stated that because men are often placed in a position that is responsible for hiring and managing new employees, gender inequality in workplace based on external appearances and attractiveness is further exacerbated.

A number of Korean studies have addressed the influence of the potential job applicants' external appearance during the employment process. Many employers require applicants to include photographs, some even asking to disclose their height and weight [9]. External appearance seems to play an even more important role for females as Kim [10] showed that the three most important factors relating to an external appearance of an interviewer during a job interview for males are: voice, speech, and general figure. However, for females, the order follows: facial expression, posture, and general figure. These apparent double standards pose different gender requirements. For males, external appearance relates to the overall cleanliness and neat presentation of self. For females, "attractiveness and beauty" seem the most important requirement [11]. This evident gender disparity must be addressed, especially at a time when more women are joining the workforce in Korea [12].

In the electronic survey, $22.4 \%$ of females indicated that they had prior plastic surgery procedures. This is consistent with previous estimates of $20 \%$, illustrating the popularity of plastic surgery among Korean young women [13]. The interviewees stated that many Korean females tend to receive plastic surgery earlier in their lifetime, mostly during their late teens and early twenties. For instance, summer between high school graduation and beginning of the college freshmen year seems to be a popular time to undergo aesthetic procedures, so that they can make a "fresh start with a brand-new look." There seem to be multiple explanations for this unique trend, largely based on societal pressure. All of the female interviewees indicated that an average Korean woman is very interested in and invests much time and effort on her appearance. There is an expectation for Kore- 
an women to be attractive, as indicated by higher number of female participants choosing parental and peer influence as their primary reasons in seeking plastic surgery ( $9 \%$ vs. $0 \%$ in males). Generally, the surgical procedures performed in South Korea are focused on facial aesthetics (77.5\% of total surgical procedures) [1], with eyelid surgery and rhinoplasty being the two most common procedures ( $31.0 \%$ and $29.6 \%$ of total surgical procedures, respectively) [1]. This is a stark difference compared to other countries with highest volume of aesthetic procedures, such as Brazil or United States, where breast and body contouring procedures make up the majority of the cases (62.7\% and $70.4 \%$, respectively) [1].

Even though aesthetic surgery is more common among females, it seems to be rapidly gaining popularity among males as well. In this study, $14.8 \%$ of males indicated that they had undergone aesthetic procedure in the past. Interestingly, almost $40 \%$ of the men without past aesthetic surgical experience indicated that they are planning to receive procedures in the future. Interviewees expressed that such popularity can be attributed to male celebrities receiving aesthetic procedures especially amplified in pervasive social media. All of the interviewees agreed that celebrities set a certain "standard of beauty." These public figures act as role models for the younger generation, not only for fashion trends, but also for ideal facial features by undergoing aesthetic surgery.

\section{Limitations}

There are some limitations to this study. First, the sample size is limiting; there were a total of 103 survey participants and 19 interviewees. Second, there was a gender imbalance among the survey participants. A total of 27 males and 76 females participated in the survey reflecting a higher female interest in the study topic. Lastly, the study may contain bias, since participants were recruited on a voluntary basis with small monetary compensation. Due to these limitations, the study subjects may not completely and accurately represent the general South Korean young adult population. However, we believe that this study provides valuable quantitative and qualitative data that adds an important insight into South Korean young adults' attitude and beliefs toward plastic surgery.

\section{Conclusions}

Aesthetic surgery is popular among South Korean young adults. There is a common belief that external attractiveness increases the potential for employment, which is a motivating factor when choosing to undergo an aesthetic procedure. Personal dissatisfaction external appearances is the most common reason for pursuing aesthetic surgery, which can be attributed to pervasive "lookism," or discrimination when not achieving cultural standards of beauty. A double standard exists currently as women are under greater pressure to achieve facial aesthetic perfection; however, there also seems to be a growing male population who desire to undergo aesthetic procedures.

\section{Notes}

\section{Conflict of interest}

No potential conflict of interest relevant to this article was reported.

\section{Ethical approval}

The study was approved by the Research Subjects Review Board of University of Rochester (approval No. RSRB 00057399) and performed in accordance with the principles of the Declaration of Helsinki. Written informed consents were obtained.

Author contribution

Study concept and design: Park RH, Langstein HN. Data acquisition and analysis: Park RH. Data interpretation: Park RH, Myers PL, Langstein HN. Obtained funding; drafting and revision of manuscript: Park RH. Critical revision of the manuscript for important intellectual content: Myers PL, Langstein HN. Study supervision: Langstein HN. Approval of final manuscript: all authors.

\section{ORCID}

Rachel H. Park https://orcid.org/0000-0003-1973-0954

Paige L. Myers https://orcid.org/0000-0003-2012-3625

Howard N. Langstein https://orcid.org/0000-0003-2458-7785

\section{References}

1. Safire W. The way we live now: 8-27-00: on language; lookism [Internet]. New York, NY: The New York Times; c2000 [cited 2016 Jan 19]. Available from https://www.nytimes.com/2000/08/27/magazine/ the-way-we-live-now-8-27-00-on-language-lookism.html.

2. Merriam-Webster medical dictionary [Internet]. Springfield, MA: Merriam-Webster Incorporated; c2005 [cited 2016 Jan 19]. Available from http://www.merriam-webster.com/.

3. Kim HS. A study on the awareness and interest about appearance of cosmetic surgery of adults [master's thesis]. Seokyeong University: Seoul; 2011. p. 31-5.

4. Hamermesh DS, Biddle JE. Beauty and the labor market. Cambridge, MA: National Bureau of Economic Research, Inc. 1993. NBER Working Paper \#4518.

5. Board of Governors of the Federal Reserve System. Foreign exchange rates for the South Korean Won [Internet]. Washington, DC: Board of Governors of the Federal Reserve System; c2016 [cited 2016 Jan 20]. Available from http://www.federalreserve.gov.

6. Gallup Korea. Investigation on Korean perception of appearance and plastic surgery [Internet]. Seoul: Gallup Korea; c2015 [cited 2017 Jan 21]. Available from http://www.gallup.co.kr/gallupdb/reportContent.asp?seqNo=656.

7. Cho YB. "Looking for female helper with neat appearance" is unlawful [Internet]. Seoul: Sisapress; c2016 [cited 2016 Sep 20]. Available from http://www.sisapress.com/journal/article/157138.

8. Wirth-Dominice L. Women in business and management: gaining 
momentum. Geneva: International Labour Organization; 2015.

9. Kim HJ. Looking for a pretty lady for this position... is this fair? [Internet]. Seoul: Segye Daily; c2015 [cited 2015 Sep 25]. Available from http://www.segye.com/content/html/2015/08/27/20150827001558. html?outurl=naver.

10. Kim HR. Influence of external images of job applicants on interviewers' judgement [master's thesis]. Korea International Culture University of Graduate: Cheongyang; 2009. p. 61-2.

11. Lim IS. Women's employment and appearance-discriminatory selec- tion. J Korean Womens Stud 2003;19:113-44.

12. Statistics Korea. Statistical data on female worker's number and the level of participation [Internet]. Daejeon: Statistics Korea; c2014 [cited 2016 Sep 20]. Available from http://kostat.go.kr/portal/korea/ index.action.

13. Swanson A. Stunning photos show why S. Korea is the plastic surgery capital of the world [Internet]. Washington, DC: Washington Post; c2015 [cited 2016 Jan 20]. Available from https://www.washingtonpost.com. 